\title{
PESQUISA COMO PRINCÍPIO EDUCATIVO NA DOCÊNCIA UNI- VERSITÁRIA: território de ensino e aprendizagem
}

RESEARCH AS AN EDUCATIVE PRINCIPLE IN TEACHING AT UNIVERSITY: a teaching and learning territory

INVESTIGACIÓN COMO PRINCÍPIO EDUCATIVO EN LA DOCENCIA UNIVERSITARIA: territorio de enseñanza y aprendizaje

\author{
Silvia Maria Nóbrega-Therrien \\ Professora Doutora do Programa de Pós-graduação em Educação da \\ Universidade Estadual do Ceará-UECE. \\ silnth@terra.com.br \\ Jacques Therrien \\ Professor Doutor do Programa de Pós-graduação em Educação da \\ Universidade Estadual do Ceará-UECE. \\ jacques@ufc.br \\ Isabel Maria Sabino de Farias \\ Professora Doutora do Programa de Pós-graduação em Educação da \\ Universidade Estadual do Ceará-UECE. \\ isabel.sabino@uece.br \\ Silvina Pimentel Silva \\ Professora Doutora do Programa de Pós-graduação em Educação da \\ Universidade Estadual do Ceará-UECE. \\ silvinapimentel@yahoo.com.br
}

\begin{abstract}
RESUMO: O estudo aprofunda dimensões da gestão pedagógica na docência universitária no campo da saúde, concebendo a pesquisa como princípio educativo na medida em que a aprendizagem à reflexividade crítica. própria a essa atividade, propicia a consolidação da autonomia profissional do educando. Tendo como suporte teórico-metodológico a epistemologia da prática docente, a etnometodologia e a ergonomia do trabalho docente configurou o desenvolvimento do objeto de investigação: a prática pedagógica de docentes universitários com atuação em pesquisa. A coleta de dados incluiu o estudo inicial dos documentos e a aplicação de questionário aos professores seguida da observação de docentes, em sala de aula e a realização de entrevistas. As atividades de análise foram desenvolvidas mediante um roteiro de categorias definidas. Os documentos analisados, enquanto conjunto de dispositivos legais evidenciaram o reconhecimento do princípio formativo da pesquisa. Por outro lado, dos 164 professores identificados nos cinco cursos da área da saúde, somente 81 (49.4\%) atuam efetivamente com pesquisa. Os dados coletados confirmaram que as iniciativas identificadas dessa integração são esparsas e frágeis, tanto na prática quanto na compreensão conceitual dos professores sobre essa dimensão da docência na formação. Configura-se, contudo, uma tendência em reconhecer sua fundamentação e a utilizá-la como estratégia de ensino e aprendizagem. De modo transversal, as atividades integradas são mais notórias entre os docentes com inserção em programas de iniciação científica, grupos de pesquisa e desenvolvimento de projetos. Professores pesquisadores com experiência consolidada denotam um modo diferenciado de lecionar e de desenvolver a atitude investigativa em seus alunos.
\end{abstract}

PALAVRAS-CHAVE: Integração ensino-pesquisa. Docência universitária. Gestão pedagógica. Epistemologia da prática. Ensino superior na saúde. 
ABSTRACT: This study broadens the dimensions of pedagogic management in university teaching in the health field, conceiving research as an educative principle, mostly as a learning strategy for critical reflexivity leading to professional autonomy of the students. With theoretical and methodological support encountered in epistemology of practice, ethnomethodology and ergonomics of teachers' work configured the development of the objective: pedagogic practice of university teachers with performance in research. Data collection included, in the first phase, the search for documents and a questionnaire with the teachers, and in the second phase, observations in the classroom and interviews. The analysis activities were developed with an itinerary of defined categories. The results from analyses of documents witnessed the recognition of research as a training principle in the set of legal provisions. Otherwise, among the 164 teachers identified from the five courses in the area of health, only 81 (49.4\%) conduct research. Data showed that the initiatives identified about this integration are sparse and fragile, as much in the teachers' practice, as from the conceptual comprehension they have on this teaching dimension and his importance in training. It is accurate to say that there is a trend in recognizing its fundaments and using it as a teaching and learning strategy. The presence of cross-cutting research is more notorious among teachers with insertion in scientific initiation programs, research groups and the development of projects. Teachers with consolidated experience denoted a differentiated method of teaching and developing an investigative posture in their students.

KEYWORDS: Teaching-research integration. University teaching. Pedagogic management. Epistemology of practice. Higher education in health.

RESUMEN: El estudio profundiza dimensiones de la gestión pedagógica en la enseñanza universitaria en el campo de la salud, concibiendo la investigación como principio educativo en la medida en que el aprendizaje de la reflexividad crítica a esa actividad propicie la autonomía profesional del estudiante. Tiendo como soporte teórico-metodológico la epistemología de la práctica docente, la etnometodología y la ergonomía del trabajo docente configuró el desarrollo del objeto de la investigación: la práctica pedagógica de profesores universitarios con actuación en la investigación. La colección de datos incluyó el estudio de los documentos y la aplicación de cuestionarios a los profesores seguidos por la observación de docentes en aula y la realización de entrevistas. Las actividades de análisis se desarrollaron a través de una guía de categorías definidas. Los documentos analizados, en cuanto conjunto de dispositivos legales evidenciaron el reconocimiento del principio formativo de la investigación. Por otro lado, de los 164 profesores identificados en los cinco cursos de la área de la salud, solamente 81 (49.4\%) actúan efectivamente con investigación. Los datos recopilados confirmaron que las iniciativas identificadas de esta integración son escasas y frágiles, tanto en la práctica como en la comprensión conceptual de los profesores sobre la dimensión de la formación docente. Establece, sin embargo, una tendencia a reconocer la investigación como estrategia de apoyo a la enseñanza y aprendizaje. Transversalmente, las actividades integradas son más notables entre los profesores con inserción en los programas de iniciación científica, grupos de investigación y desarrollo de proyectos. Profesores investigadores con experiencia consolidada demuestran una forma diferente de enseñar y desarrollar una actitud investigativa en sus alumnos.

PALABRAS CLAVE: Integración enseñanza-investigación. Docencia universitaria. Gestión pedagógica. Epistemología de la práctica. Enseñanza superior en la salud. 
PESQUISA COMO PRINCIPIO EDUCATIVO | Silvia Maria Nóbrega-Therrien e et. al.

\section{1 | A PESQUISA COMO TERRITÓRIO DE FORMAÇÃO}

O projeto que forneceu os subsídios para elaboração deste artigo teve por finalidade aprofundar o conhecimento e as dimensões da gestão pedagógica na docência universitária no campo da saúde, concebendo a pesquisa como princípio educativo. A proposta agregou integrantes de três grupos de pesquisa ${ }^{1}$ que compartilham interesses e preocupações em torno do trabalho docente na sua dimensão de gestão pedagógica entendida como:

[...] práxis transformadora de um sujeito-professor em interação situada com outro sujeitoaluno na qual a aprendizagem, centrada na produção de identidade pela construção de novos saberes, sentidos e significados, procede pela ação comunicativa da dialogicidade em direção ao entendimento entre ambos, no horizonte de uma emancipação humana e profissional fundada no ser social (THERRIEN, 2012, p. 115).

Nesse sentido, o estudo foi desenvolvido como uma contribuição para a reflexão sobre as funções de ensino e pesquisa, constituintes da instituição universitária e sua articulação dialética para a formação e emancipação de sujeitos, ou seja, sobre a aprendizagem à vida profissional e cidadã que passa pela articulação das funções de produção de saberes e conhecimentos e de mediação a compreensão e domínio destes na relação intersubjetiva entre educador e educando em contexto de educação superior. Destaca-se, portanto, a integração entre essas funções na docência, em particular sobre a prática dos formadores atuantes em/com pesquisa em cursos de graduação.

Nesta formulação, a investigação teve por objetivo central compreender a gestão pedagógica própria à vinculação entre a prática e as atividades de ensino e de pesquisa e sua integração com os conteúdos curriculares no âmbito da docência universitária, na área de saúde, bem como sua adequação às diretrizes nacionais da proposta de formação profissional, na legislação vigente, para os professores da educação superior.

A este propósito central foram formulados objetivos específicos tais como: caracterizar a gestão pedagógica das atividades ligadas à pesquisa, em cursos de graduação em saúde, assim como os contextos em que se concretizam, as dificuldades e formas de enfrentamento desenvolvidas para favorecer o acesso aos saberes e conhecimentos neste campo, junto aos alunos nas situações cotidianas de ensino e aprendizagem; conhecer o que pensam os professores da área da saúde responsáveis por disciplinas com vinculação a pesquisa ou com experiência investigativas acerca de sua formação profissional e sua relação com a formação para a pesquisa; contribuir para a reflexão sobre a integração ensino e pesquisa na docência universitária, em particular acerca da prática dos formadores em saúde, atuantes em disciplinas e atividades relacionadas à pesquisa; favorecer a consolidação de intercâmbio dos grupos de pesquisa e de trabalho cooperativo entre jovens doutores e pesquisadores experientes na universidade.

O texto do artigo ora apresentado aborda predominantemente, elementos relativos ao desenvolvimento metodológico e processual do estudo, explicitando brevemente uma problemática e sua fundamentação teórica necessária para outros espaços de publicação e divulgação pública, considerando de modo particular, os limites de expansão de trabalhos em revistas. Inicia com breve relato do suporte teórico encontrado em autores de referência que abordam a temática em

\footnotetext{
${ }^{1}$ Grupos de Pesquisa Educação, História e Saúde Coletiva (da UECE/Centro de Ciências da Saúde); Educação, Cultura Escolar e Sociedade (da UECE/Centro de Educação), e Saber e Prática Social do Educador (da UFC/ Faculdade de Educação).
} 
PESQUISA COMO PRINCIPIO EDUCATIVO | Silvia Maria Nóbrega-Therrien e et. al.

foco, seguido ao processo de construção teórico-metodológica do estudo e seus sujeitos, abordando os procedimentos de investigação, organização e análise dos dados, para no remate, relatar achados da investigação.

\section{2 | ALGUMAS CONSIDERAÇÕES SOBRE A INTEGRAÇÃO ENSINO E PESQUISA EM CON- TEXTO UNIVERSITÁRIO}

A preocupação com a integração ensino/pesquisa no campo da docência universitária consolidou-se pela emergência do pensamento a respeito do professor pesquisador e o professor reflexivo no cenário educacional, sobretudo brasileiro, o que aguça o debate em torno dessa relação na formação docente.

A temática do estudo inclina seu foco para o docente universitário e a gestão pedagógica de seus saberes. Inquietações registradas no texto sobre "Formação para além do ensino na docência universitária” (THERRIEN; NÓBREGA-THERRIEN, 2009, p. 99) apontam para reflexões nas quais se objetiva identificar elementos constituintes da práxis docente e da aprendizagem em busca de entendimento da racionalidade que dá suporte a esta prática.

Tendo por pressuposto o paradigma da epistemologia da prática como categoria epistemológica de análise, diversos autores de referência deram suporte à análise da proposta que se ancora em Demo (2001, p. 16): "Pesquisa é processo que deve aparecer em todo trajeto educativo, como princípio educativo que é, na base de qualquer proposta emancipatória. [...] o melhor saber é aquele que sabe superar-se".

O estudo procede em torno de questões identificadas por Schön (1983, 2000); Zeichner (1993, 2003); Cunha (1998); Ludke (2001); André (1997, 2001) e Pimenta (2006) no exame dos impasses que permitem melhor compreensão dos processos de ensino-aprendizagem nos contextos de instituições de nível superior. O professor reflexivo, a reflexão-na-ação e a análise dos níveis de reflexividade (SACRISTÁN, 1999) requeridos para a compreensão e, consequentemente, a produção de saberes em contexto universitário de aprendizagem, que são dimensões a requererem uma formação para a docência que dê conta da relação dialética entre teoria e prática, vivenciada em contextos que integram o binômio ensino e pesquisa (FARIAS, 2007).

A tematização sobre a formação de professores ancorada na relação ensino e pesquisa (ANDRÉ, 1997; CUNHA, 1998; LUDKE, 2001; NÓBREGA-THERRIEN; THERRIEN, 2006) apontam que a integração dessa atividade na ação docente cotidiana envolve uma finalidade pedagógica. No entendimento de André (2001, p. 55) constitui-se uma "prática mobilizadora de reflexão sobre o trabalho docente" que para Therrien e Nóbrega-Therrien (2009, p.103) é "sustentada por uma racionalidade pedagógica fomentadora de uma 'práxis' educativa que abra caminhos de aprendizagens à 'vida' contemporânea". Por fim, postula-se o argumento de que o "envolvimento sistemático em atividades de pesquisa favorece o desenvolvimento de racionalidades que dão suporte a práticas reflexivas geradoras de questionamentos e argumentações" (ZEICHNER, 2003, p. 208). Estes, por sua vez, conduzem à melhor compreensão dos significados dos saberes objetos do ensino e, portanto, a aprendizagens mais significativas e autônomas dos alunos.

\section{3 | SITUANDO A INVESTIGAÇÃO NO SEU CAMINHO METODOLÓGICO}

O ensino é uma atividade interativa que acontece em contexto situado, promovendo uma relação entre sujeitos distintos e com propósitos diversos que precisam interagir para concretizar intenções de aprendizagem. Essa proposição conduz a uma indagação fundante para a proposta de estudo: como investigar o trabalho docente através do saber produzido em contexto real de 
prática? Tendo como postulado de base que a cognição ou a ação são incompreensíveis fora de um contexto e que, portanto, devem ser estudadas in situ e teorizadas em relação à situação, o objeto de estudo anunciado, a saber, a prática pedagógica de professores universitários com atuação em pesquisa na área da saúde, encontra suporte metodológico na abordagem da etnometodologia e da ergonomia do trabalho docente.

A análise do saber-ensinar bem como do saber-pesquisar aponta para dois polos, a atividade e a situação, vertentes que a ergonomia leva em conta buscando integrá-las em um quadro analítico geral. O trabalho docente, portanto, é abordado sob esse ângulo por ser uma práxis ligada à concepção e articulada a atividades e execução de tarefas. Assim como em outros estudos sobre o saber-ensinar, e por complemento sobre o saber-pesquisar em contexto de ensino, a presente investigação encontra suporte nos pressupostos teóricos e metodológicos da ergonomia do trabalho docente e da cognição situada, abordagens que nos aproximam igualmente da etnometodologia, além da epistemologia da prática (THERRIEN; LOIOLA, 2001, p. 113-123).

Ademais, convém esclarecer que a ambiguidade da noção de trabalho docente, decorrente da abrangência e da complexidade do seu alcance conceitual, requer situar o contexto que lhe proporciona significado específico quando se trata de analisar os elementos que o constituem. O enfoque de referência, no estudo em pauta, nos instiga a abordá-lo na perspectiva do trabalho pedagógico ancorado em relações intersubjetivas de ensino/aprendizagem, fenômeno que abrange a gestão pedagógica das atividades de formação.

O local da investigação foi restrito à Universidade Estadual do Ceará (UECE), no seu Centro de Ciências da Saúde (CCS). Foram escolhidos os cinco cursos da área e o corpo docente que constitui a referida Unidade-mater: Medicina, Enfermagem, Nutrição, Ciências Biológicas e Educação Física. O universo dos que participaram do estudo foi definido considerando-se os seguintes critérios: ser efetivo do quadro docente dessa IES; atuar como professor universitário com vínculo com pesquisa, ou seja, que participa de grupos ou desenvolve projeto individual de pesquisa e/ou que ministra disciplina relacionada à investigação científica; aceitar de participar do estudo.

A coleta de dados incluiu, na primeira fase, o mapeamento e o estudo dos documentos relacionados às Diretrizes Curriculares e o Projeto Politico-Pedagógico de cada um dos cinco cursos da área da saúde e, ainda, a aplicação de questionário aos seus professores, mantendo-se as especificidades próprias a cada contexto. Na segunda fase foi realizada a observação de docentes em sala de aula, a qual foi completada com entrevistas de explicitação para esclarecimentos das práticas e conteúdos observados. O tempo de observação do professor na sala de aula teve como base uma 'unidade didática' do programa de sua disciplina. A coleta de dados dessa fase foi desenvolvida mediante roteiro previamente elaborado para posterior análise estruturada em torno de categorias definidas.

\section{4 | SEQUÊNCIA DAS ATIVIDADES E ORGANIZAÇÃO DOS ACHADOS}

A sequência de atividades previstas no cronograma de desenvolvimento estabelecido no projeto foi dividida em três momentos. Inicialmente é relatada a organização de um conjunto de 'Seminários Temáticos de Aprofundamento', dedicados à leitura e debate de referenciais teórico-metodológicos concernentes às questões principais de interesse e ao estabelecimento de categorias centrais, para a análise dos dados. Em seguida, são apresentados os elementos oriundos da documentação coletada voltada principalmente, à descrição dos cursos e do corpo docente. No terceiro momento, relatamos os procedimentos de formulação das categorias e subcategorias, para a organização e análise dos dados oriundos das observações e entrevista da segunda fase da pesquisa. 


\subsection{Os Seminários Temáticos: primeiras aproximações}

Objetivando dar encaminhamento aos propósitos do projeto, o trabalho da equipe teve início com um período de formação desenvolvido em sessões regulares de estudo, visando à discussão de pontos conceituais sobre o objeto de investigação e aspectos vinculados a sua operacionalização. Foram utilizados textos de autores de referência acerca de temáticas de interesse. Essa atividade foi alvo de registro descritivo sistemático, no formato de memórias, documento sempre socializado no encontro subsequente. Como resultado principal dessa agenda, são ressaltados a definição dos temas objeto de estudo e a discussão de referenciais para a constituição das categorias iniciais estruturantes da coleta e análise de dados.

\subsection{Coleta da documentação, inventário e proposta de análises}

O primeiro momento de trabalho de campo permitiu um inventário de informações sobre os cinco cursos, bem como a composição do corpo docente responsável pelas disciplinas e as atividades de pesquisa. Foram visitadas as coordenações de cursos, utilizadas informações disponíveis no Plano de Atividade Docente (PAD) e no site da Pró-Reitoria de Graduação-PROGRAD/UECE (http://www.uece.br/prograd/), além de consultar os currículos lattes dos docentes no site do CNPq.

Dos 164 professores identificados nos cinco cursos da área da saúde, somente 81 (49.4\%) atuam com pesquisa, conforme os critérios de seleção definidos. Foi para esse universo que o estudo voltou sua atenção. Os dados foram sistematizados no quadro 1 a seguir.

Quadro 1 - Caracterização do universo de sujeitos da pesquisa nos cursos do Centro de Ciências da Saúde (CCS) da UECE (semestre 2009.2), Fortaleza-CE, 2011.

\begin{tabular}{|c|c|c|c|c|c|c|c|c|}
\hline Curso & Efetivo & Substituto & Total & $\begin{array}{c}\text { Atua } \\
\text { somente } \\
\text { em } \\
\text { disciplinas } \\
\text { de } \\
\text { pesquisa }\end{array}$ & $\begin{array}{c}\text { Participa } \\
\text { somente } \\
\text { de }\end{array}$ & $\begin{array}{c}\text { Atua em } \\
\text { Grupo } \\
\text { de } \\
\text { Pesquisa } \\
\text { e Grupos } \\
\text { de }\end{array}$ & $\begin{array}{c}\text { Total } \\
\text { de } \\
\text { Pesquisa } \\
\text { sujeitos } \\
\text { da } \\
\text { Pesquisa }\end{array}$ & $\begin{array}{c}\text { Sem } \\
\text { a a ç ã o } \\
\text { em } \\
\text { pesquisa }\end{array}$ \\
\hline C. Biológicas & 22 & 05 & 27 & - & 11 & 02 & 13 & 14 \\
\hline Educ. Física & 13 & 05 & 18 & 03 & 01 & - & 04 & 14 \\
\hline Nutrição & 27 & 06 & 33 & 03 & 14 & - & 17 & 16 \\
\hline Enfermagem & 34 & 06 & 40 & - & 25 & 01 & 26 & 14 \\
\hline Medicina & 41 & 05 & 46 & - & 17 & 04 & 21 & 25 \\
\hline Total Geral & 137 & 27 & 164 & 06 & 68 & 07 & 81 & 83 \\
\hline
\end{tabular}

Fonte: Elaborado pelos autores.

Em relação aos documentos, procedeu-se à coleta de materiais relacionados às diretrizes curriculares de formação de professores em nível superior, bem como dos projetos político-pedagógicos (PPP) dos cursos de graduação sob exame. O estudo desses materiais foi realizado, com o objetivo de identificar os referenciais normativos e conceituais definidos pela Instituição e de acordo com os dispositivos legais que evidenciam o elemento de reconhecimento do princípio formativo da pesquisa. 
Em paralelo a essas atividades, foi realizado o contato inicial com os professores, seja de forma presencial ou por via eletrônica, para solicitar sua participação na investigação. O questionário foi o instrumento utilizado, sendo composto por questões que permitiram denotar um perfil da atuação em pesquisa dos professores vinculados aos cinco cursos de graduação do CCS em foco. $O$ instrumento aplicado indagava, também, a respeito da disponibilidade para continuar participando da investigação e indicava as modalidades em que esta participação poderia acontecer - apenas para entrevista ou para entrevista e observação da sua prática. Algumas dificuldades foram encontradas no campo que limitaram o alcance do universo inicialmente previsto, entre outras, o afastamento temporário de alguns professores.

Dos 61 respondentes ${ }^{2}, 34$ optaram por se submeterem à entrevista e observação. Considerando a quantidade de sujeitos e o volume do trabalho de campo decorrente, a amostra foi reduzida à escolha de dois professores em cada curso para essa atividade. Da seleção final de dez participantes, com referência em critérios de equivalência, um não aceitou ser observado. As observações das situações de aula foram realizadas priorizando-se "uma sequência/unidade didática completa". As entrevistas de explicitação, em sua maioria, foram realizadas em uma sessão, após a observação do professor em ação, na sala de aula.

\subsection{Sobre a organização dos dados para as análises}

Este momento da investigação - voltado principalmente para a construção de categorias de análise adequadas aos objetivos da pesquisa e à situação encontrada na coleta dos dados - foi orientado pela compreensão de que a interpretação e a análise estão contidas no mesmo movimento: o de considerar atentamente os dados encontrados, em busca de possíveis respostas para as questões norteadoras do estudo, entendendo-as como uma produção oriunda também da capacidade humana de articular o empírico e o teórico, atribuindo-lhe significado. Considerando os tipos de dados utilizados, oriundos tanto da entrevista e da observação, quanto dos documentos governamentais e institucionais, optou-se pela análise qualitativa das informações, mediante a categorização temática, com a triangulação dos dados.

A análise da documentação consultada (diretrizes, resoluções, pareceres e projetos político-pedagógicos dos cursos pesquisados) demandou a realização de sucessivas leituras, guiadas por critérios e procedimentos que favorecessem a explicitação de elementos (ideias, expressões) relacionados a temas e categorias centrais, estabelecidas por ocasião dos Seminários Temáticos. O mapeamento realizado serviu de esteio à elaboração das interpretações sobre o assunto investigado, possibilitando o cruzamento das informações, seja para complementá-las, contrapô-las e ou problematizá-las. Este procedimento foi realizado nos cinco cursos da área da saúde, considerando a documentação específica de cada uma, o que possibilitou constituir o marco legal vigente sobre a regulamentação da pesquisa no processo de formação universitária, contexto em que se situa e se desenvolve a prática docente na Educação Superior.

Os dados provenientes do questionário referentes ao perfil de atuação em pesquisa dos docentes receberam tratamento analítico quantitativo, destacando formação, faixa etária, vínculo de trabalho, participação em grupos e projetos de pesquisa, bem como o envolvimento com atividade de orientação e o efetivo exercício da docência. A análise permitiu, de início, identificar os professores que mantinham vínculo com atividades de pesquisa e informação necessária para a defini-

${ }^{2}$ Do total de 61 professores que responderam ao questionário inicial, encomtram-se: Ciências Biológicas (08), Educação Física (04), Nutrição (10), Medicina (15) e Enfermagem (24). 
ção dos sujeitos das atividades a seguir. O procedimento propiciou a composição de um retrato preliminar de tais sujeitos com a atividade de pesquisa no âmbito de suas funções docentes na Universidade.

A análise dos dados provenientes das observações buscava assegurar a aproximação à prática docente universitária, fornecendo elementos indiciais sobre a integração pesquisa e ensino em situação real de trabalho. Os registros das observações das aulas foram objeto de leitura, discussão e confrontação com os discursos dos professores, tornando-se elementos de referência na sistematização do relatório final, para ilustrar situações e posicionamentos.

Os dados das entrevistas possibilitaram o acesso ao discurso prático dos docentes mediante a categorização temática. É importante assinalar-se que o processo de categorização viabiliza uma definição prévia de categorias abrangentes, estruturadas inicialmente, na formulação do roteiro de entrevista e sua consolidação definitiva pós-coleta dos dados, considerando o conteúdo das informações encontradas no trabalho de campo.

Para tanto, procedeu-se à leitura intensiva das entrevistas, seguida da identificação das ideias ou expressões recorrentes, agrupando-as em torno de conceitos mais gerais. Com base nesse procedimento, constituíram-se três grandes blocos de categorias empíricas:

a) Percepção do sujeito pesquisado sobre o modo como ele ensina. Com esta categoria, buscou-se conhecer a perspectiva do professor sobre a própria prática de ensino. Teve como foco a explicitação e a compreensão de elementos fundantes da ação, ou seja, de ideias, concepções e práticas orientadoras do seu agir docente. A categoria abrange desde a atividade de planejamento, conteúdo, aspectos sobre a condição do aluno para aprender, relação professor e aluno, avaliação, concepções sobre ensino e aprendizagem, saberes e experiências intervenientes na sua ação pedagógica. O quadro 2 permite visualizar essa categorização.

Quadro 2 - Percepção do sujeito pesquisado sobre o modo como ensina: categoria constituída como base para análise das entrevistas dos professores nos cinco cursos do CCS pesquisados na UECE, Fortaleza-CE, 2011.

\begin{tabular}{|c|c|c|}
\hline Categoria & Subcategorias & Aspectos contemplados nas subcategorias \\
\hline \multirow{3}{*}{$\begin{array}{l}\text { Percepção do sujeito } \\
\text { pesquisado sobre o modo } \\
\text { como ensina }\end{array}$} & \multirow{3}{*}{ Planejamento } & Caminho para o planejamento \\
\hline & & Organização do tempo curricular \\
\hline & & Modificações necessárias para aproximação da prática \\
\hline \multirow{14}{*}{$\begin{array}{l}\text { (Elementos fundantes da } \\
\text { ação didática do professor) }\end{array}$} & \multirow{3}{*}{$\begin{array}{l}\text { Atenção à } \\
\text { Condição do aluno }\end{array}$} & Diferenças entre turmas (turmas diurnas /turmas noturnas) \\
\hline & & Necessidades do aluno \\
\hline & & Forma de estudo dos alunos \\
\hline & \multirow{4}{*}{ Conteúdo } & Foco no programa \\
\hline & & Prática de seleção dos conteúdos \\
\hline & & Adequação a turma \\
\hline & & Articulação com outras disciplinas \\
\hline & \multirow{2}{*}{$\begin{array}{l}\text { Relação } \\
\text { professor-aluno }\end{array}$} & Foge da relação unidirecional que vivenciou na escola \\
\hline & & Resistência de alguns alunos no primeiro semestre. \\
\hline & \multicolumn{2}{|l|}{ Avaliação } \\
\hline & \multirow{4}{*}{ Fundamentos } & Concepção de ensino \\
\hline & & Concepção de aprendizagem \\
\hline & & Saberes profissionais docentes \\
\hline & & Experiências \\
\hline
\end{tabular}

Fonte: Elaborado pelos autores. 
b) Estratégias de iniciação à construção do conhecimento na aula universitária. Esta categoria temática focalizou as estratégias de ensino utilizadas pelo professor para promover a aprendizagem discente no contexto da aula na Universidade, as dificuldades encontradas na iniciação do aluno à construção do conhecimento (aprendizagem), bem como a adesão do aprendiz à prática pedagógica por ele desenvolvida. Contempla ainda, aspectos relacionados à percepção dos docentes sobre a contribuição de suas práticas para o desenvolvimento da postura investigativa entre seus alunos. O quadro 3 denota essa categorização.

Quadro 3 - Estratégia de iniciação à construção do conhecimento na aula universitária: categoria constituída como base para análise das entrevistas dos professores nos cinco cursos do CCS pesquisados na UECE, Fortaleza-CE, 2011.

\begin{tabular}{|c|c|c|}
\hline Categoria & Subcategorias & Detalhamento da subcategoria \\
\hline \multirow{14}{*}{$\begin{array}{l}\text { Estratégias de ensino utilizadas } \\
\text { na iniciação à } \\
\text { construção do conhecimento }\end{array}$} & \multirow{7}{*}{ Estratégias de ensino } & Estudo de caso \\
\hline & & Estudos teóricos/leituras \\
\hline & & Discussão de situações práticas \\
\hline & & Provocação de diálogo \\
\hline & & Trabalho Escrito \\
\hline & & Trabalho em grupo = seminário \\
\hline & & Estimulo ao uso de recursos tecnológicos \\
\hline & \multirow{4}{*}{ Dificuldades encontradas } & Recursos didáticos \\
\hline & & Carga horária insuficiente \\
\hline & & Natureza do vinculo de trabalho \\
\hline & & Condição para o desenvolvimento de pesquisa \\
\hline & \multirow{2}{*}{ Adesão do aluno } & Percepçôes sobre a adesão dos alunos \\
\hline & & Resistência dos alunos \\
\hline & \multicolumn{2}{|c|}{ Percepção dos docentes sobre o desenvolvimento da postura investigativa } \\
\hline
\end{tabular}

Fonte: Elaborado pelos autores.

c) Integração pesquisa e ensino na aula universitária. Esta categoria temática reúne elementos sobre o entendimento dos sujeitos da investigação acerca do conceito de pesquisa e de integração pesquisa e ensino, bem como sua percepção quanto à realização do processo em sua prática docente de sala de aula. Agrega também, registros sobre dificuldades no exercício da integração pesquisa e ensino na aula universitária. O quadro 4 permite visualizar essa categorização.

Quadro 4 - Integração pesquisa e ensino na aula universitária: categoria constituída como base para análise das entrevistas dos professores nos cinco cursos do CCS pesquisados na UECE, Fortaleza-CE, 2011.

\begin{tabular}{|l|l|l|}
\hline Categoria & \multicolumn{1}{|c|}{ Subcategorias } & Detalhamento da Subcategoria \\
\hline \multirow{4}{*}{$\begin{array}{l}\text { Integração pesquisa e } \\
\text { Ensino, na aula universitária }\end{array}$} & Dificuldades para realizar integração pesquisa c ensino \\
\cline { 2 - 3 } & Concep̧̧̃̃o de interação da pesquisa ao ensino \\
\cline { 2 - 3 } & Concep̧̧̃̃o de pesquisa \\
\cline { 2 - 3 } & $\begin{array}{l}\text { Percepções dos docentes } \\
\text { pesquisados sobre o tema }\end{array}$ & $\begin{array}{l}\text { Teoria em confronto com a prática } \\
\text { ensino }\end{array}$ \\
\cline { 2 - 3 } & & $\begin{array}{l}\text { A proposta curricular do curso relacionada å } \\
\text { pesquisa }\end{array}$ \\
\hline
\end{tabular}

Fonte: Elaborado pelos autores. 
PESQUISA COMO PRINCIPIO EDUCATIVO | Silvia Maria Nóbrega-Therrien e et. al.

As três categorias indicadas nos quadros acima se revelaram profícuas no exame detido das entrevistas com os professores nos cinco cursos pesquisados. Verificou-se em alguns cursos, uma ou outra variação, na identificação das subcategorias e no detalhamento de aspectos, sem, contudo, distar do conjunto.

\section{5 | ANÁLISES DOS DADOS E SUA CONSOLIDAÇÃO}

\subsection{Professores com vínculo com pesquisa: quem são e quais atividades de pesquisa desenvolvem (análise do questionário)}

As informações coletadas na primeira fase dos trabalhos permitiram identificar a totalidade do corpo docente dos cinco cursos de graduação da área da saúde, em Fortaleza: Enfermagem, Medicina, Educação Física, Ciências Biológicas e Nutrição. O recorte para o perfil dos docentes com vínculo com pesquisa forneceu informações instigantes sobre a relação desses profissionais de docência com a pesquisa.

Dos 164 professores identificados, como consta no quadro 1, apresentado anteriormente, 137 registravam vínculo de trabalho como efetivo, ao passo que 27 eram substitutos. Nestes cinco cursos, 81 professores mantinham algum vínculo com a pesquisa, seja ministrando disciplinas nessa área, participando de grupos de pesquisa (na modalidade de coordenador, pesquisador ou colaborador), orientando, desenvolvendo projetos e ou participando de pós-graduação. Por motivos diversos, apenas 61 destes últimos responderam ao questionário destinado a traçar seus perfis, como pesquisadores e docentes na Universidade.

A faixa etária média desses 61 profissionais situa-se de 40 a 49 anos. No curso de Nutrição, quatro professores (40\%) estão entre 20 e 29 anos e, no curso de Educação Física, dois (50\%) estão entre 30 e 39 anos. Nove docentes do curso de Medicina têm entre 50 a 59 anos, enquanto $10(41 \%)$ dos 26 professores do curso de Enfermagem se encontram na faixa de 40 a 49 anos. Com relação ao gênero, 41 dos 61 respondentes pertencem ao sexo feminino. Chama atenção o curso de Nutrição, pois todos os docentes são do sexo feminino.

Prevalece como formação profissional dos professores com atuação em pesquisa, o bacharelado (42 docentes), seguidos pelos licenciados (cinco docentes) e um grupo de 14 profissionais com ambas as formações. A incidência de bacharéis é mais acentuada nos cursos de Enfermagem (16) e Medicina (13). Um caso particular encontra-se no curso de Educação Física, pois, dos quatros professores com atuação em pesquisa, dois são licenciados e dois possuem bacharelado e licenciatura. O quadro 5 exprime este dado.

Quadro 5 - Distribuição dos professores com atuação em pesquisa, por cursos do CCS da UECE e por tipo de formação (semestre 2009.2), Fortaleza-CE, 2011.

\begin{tabular}{|l|l|l|l|}
\hline \multicolumn{1}{|c|}{ Cursos } & $\begin{array}{l}\text { Professores com } \\
\text { bacharelado }\end{array}$ & $\begin{array}{l}\text { Professores com } \\
\text { licenciatura }\end{array}$ & $\begin{array}{l}\text { Professores com } \\
\text { bacharelado e } \\
\text { licenciatura }\end{array}$ \\
\hline Ciências Biológicas & 4 & 2 & 2 \\
\hline Educaçăo Fisica & - & 2 & 2 \\
\hline Nutrição & 9 & - & 1 \\
\hline Enfermagem & 16 & 1 & 7 \\
\hline Medicina & 13 & - & 2 \\
\hline \multicolumn{1}{|c|}{ Total } & $\mathbf{4 2}$ & $\mathbf{0 5}$ & $\mathbf{1 4}$ \\
\hline
\end{tabular}

Fonte: Elaborado pelos autores. 
PESQUISA COMO PRINCIPIO EDUCATIVO | Silvia Maria Nóbrega-Therrien e et. al.

No que diz respeito aos Grupos de Pesquisa, dos cinco cursos que compõem o universo do estudo, 57 professores atuam em 37 equipes, com as mais diversas temáticas, correlatas às especificidades de sua área de formação ou de atuação. Predomina a maior quantidade de professores que participam de grupos de pesquisa nos cursos de Enfermagem e Medicina, com respectivamente 15 e 12 Grupos cadastrados no Diretório do CNPq. Situação inversa é observada no curso de Educação Física, que dispõe apenas de dois Grupos de Pesquisa.

O desenvolvimento de projetos é outro indicador relevante no perfil de atuação dos 61 pesquisadores respondentes do questionário. Nos cinco cursos estudados 49 professores declararam participar de projetos de pesquisa, destacando-se na categoria coordenadores de projetos os docentes dos cursos de Enfermagem (17) e Medicina (12). Em seguida vêm os cursos de Ciências Biológicas (8) e Nutrição (5).

Na triangulação das informações documentais e naquelas oriundas de questionário respondido por professores com atuação em pesquisa, evidencia-se ainda, em todos os cursos analisados - considerando o atual currículo (pós-diretrizes) - a presença de componentes diretamente vinculados à pesquisa, tais como: "Metodologia da Pesquisa I e II", "Métodos e Técnicas de Pesquisa", "Métodos da Pesquisa em Enfermagem", "Investigação em Nutrição", "Métodos de estudo e de pesquisa", entre outros. Este fato mostra a importância concedida nos currículos à formação em pesquisa dos graduandos. Por outro lado, a análise da carga docente semanal (CDS) dos últimos semestres revelou certa tendência de concentração dessas disciplinas entre um reduzido grupo de professores, notadamente mestres e doutores. No curso de Educação Física, no entanto, as disciplinas de pesquisa são assumidas por professores sem vínculo efetivo com a Universidade.

$\mathrm{O}$ cruzamento dos indicadores relativos aos docentes que ministram disciplinas de pesquisa e o vínculo destes, com grupos de pesquisa ou atividade de orientação de trabalhos investigativos ou ainda participação em programa institucional de iniciação científica, revela que tais experiências não parecem ser consideradas para a lotação dos professores nos componentes curriculares da área de pesquisa. A titulação se sobressai como elemento norteador dessa decisão, no âmbito da gestão pedagógica das coordenações de curso, com exceção do curso de Educação Física. Embora este seja um programa de graduação que cobre significativo número das disciplinas voltadas para a pesquisa (Métodos e Técnicas de Pesquisa, Metodologia da Pesquisa Aplicada à Educação Física, Monografia I e II), nota-se que é também, aquele cujo o corpo docente se mostra menos envolvido com esta atividade. Dos seus 18 professores (13 efetivos e cinco substitutos) três são responsáveis pelas disciplinas da área de pesquisa (um efetivo com título de mestre e dois substitutos especialistas). Foi o único curso identificado, lotando professores sem pós-graduação strictosensu, para assumir a função de orientador.

Outro dado que permite dimensionar a experiência dos docentes com pesquisa reside na participação em grupos de pesquisa, cadastrados no diretório do CNPq. A Educação Física aparece como aquele com menor expressão, pois apenas um docente participa de grupo de pesquisa, na condição de pesquisador. Tal circunstância causa preocupação, especialmente considerando a inexistência, até o momento, de grupo de pesquisa originariamente criado para investigar questões específicas da área. Os demais cursos tendem a buscar a associação entre pares, exceto em Medicina, onde se nota certa dispersão dos professores, uma vez que os grupos são, preferencialmente, compostos por apenas um professor do curso.

5.2 A integração pesquisa e ensino na prática docente: o que ocorre na sala de aula universitária (análise das entrevistas e observações)

Adentrar a sala de aula não é tarefa das mais simples, especialmente quando o propósito é 
PESQUISA COMO PRINCIPIO EDUCATIVO | Silvia Maria Nóbrega-Therrien e et. al.

aproximar a lente sobre a aula universitária, contexto que só recentemente passou a constituir objeto de estudo na investigação educacional. Atentos a este fato, os responsáveis pela aplicação do questionário perguntaram aos docentes sobre a disponibilidade para continuar participando da investigação, assinalando a modalidades em que esta participação poderia acontecer: apenas sendo entrevistado; ou ser entrevistado e observado em sua prática.

\subsection{Os sujeitos entrevistados e observados}

Dos 61 docentes que responderam ao questionário, 34 aceitaram ser entrevistados e observados. Pretendia-se, no entanto, observar e entrevistar uma amostra de dois professores de cada curso, o que nem sempre foi possível, como ocorreu com os cursos de Medicina e Educação Física. Nesses, os professores observados foram em menor número do que os entrevistados. Concederam entrevista nove docentes dos cinco cursos e oito permitiram a observação da prática pedagógica em sala de aula.

Tendo como característica comum, a prática de ensino e a prática de pesquisa, elaborou-se um roteiro de observação e de entrevista em torno de categorias que permitissem compor um retrato profissional desses sujeitos, para a compreensão dos seus modos de integração dessas práticas, como atividades pedagógicas de aprendizagem aos saberes.

\subsection{0 que ocorre na sala de aula universitária?}

Os achados foram organizados por curso, tomando como referências as três categorias que orientaram a análise das entrevistas junto aos professores, quais sejam:

a) a percepção do sujeito pesquisado sobre como ele ensina, cujos elementos objetivam explicitar os elementos fundantes da ação didática do professor;

b) as estratégias de ensino utilizadas na iniciação à construção do conhecimento, agregando informações sobre a concretização da prática de ensino;

c) a integração pesquisa e ensino na aula universitária, que reúne elementos sobre a percepção dos docentes acerca da concretização desse proces, em sua prática.

As observações da prática pedagógica constituíram os subsídios analíticos para confirmar ou confrontar as posições assumidas nas entrevistas, pelos sujeitos do estudo. A apresentação desse cenário, objeto principal do estudo, é relatada nas considerações conclusivas apresentadas a seguir.

\section{6 | CONSIDERAÇÕES FINAIS}

A temática "Pesquisa como principio educativo na docência universitária: território de ensino e aprendizagem" constitui um pressuposto de compreensão do trabalho pedagógico, sob o enfoque da gestão integrada de duas funções fundantes da universidade como relação dialética que se complementa. Como práticas carregadas de teoria, pesquisa e ensino convergem nos processos de aprendizagem aos saberes na formação de profissionais autônomos. Ao desvelar o cenário de ação do professor universitário, o estudo busca a compreensão das intencionalidades, da racionalidade e dos saberes constituintes de uma prática de sujeitos que integram seu fazer de pesquisa e de ensino, como mediadores de aprendizagem.

A análise desse fenômeno encontrou na abordagem etnometodológica e da ergonomia do trabalho docente referencial, apropriado à observação de saberes e práticas em contexto de ação situada que expressam intencionalidades, motivos e objetivos que fundamentam o fazer docente. 
PESQUISA COMO PRINCIPIO EDUCATIVO | Silvia Maria Nóbrega-Therrien e et. al.

Nisto reside a compreensão da epistemologia da prática concebida, como estudo da constituição (metodologia e pressupostos) dos conhecimentos válidos ou como a racionalidade construída nas interações com os fatos e a forma como o sujeito, pelo uso de variadas formas de raciocínio, orienta suas ações. O relato do desenvolvimento do estudo em foco pretendeu ser um aporte em torno desse fenômeno, percebido como paradigma em constituição. Essas considerações referem particularmente à trajetória teórico-metodológica do estudo.

A análise documental permitiu esclarecer como a pesquisa aparece como componente curricular, tanto na legislação vigente sobre a formação profissional em nível superior, como nos princípios da instituição universitária brasileira, nas diretrizes educacionais vigentes no País e nos Projetos Pedagógicos dos cinco cursos de graduação investigados, ofertados por uma IES pública estadual.

A inserção no micro contexto da sala de aula na universidade aportou elementos sobre como ensina o professor pesquisador, nesse espaço-tempo da formação profissional indicativos de que o rompimento com a concepção de pesquisa acadêmica ainda perfila como um desafio.

Nas últimas décadas, a UECE realiza investimentos na constituição da cultura de pesquisa, no âmbito da formação profissional por ela ofertada, cenário em que os professores com formação e experiência em pesquisa, assumem papel primordial. Nesse sentido, preocupa a constatação de que parcela considerável dos 164 professores identificados nos cinco cursos de graduação, analisados 83 deles, mantenha distanciamento de atividades relacionadas à pesquisa, sendo Ciências Biológicas $(n=14)$, Educação Física $(n=14)$, Enfermagem $(n=14)$, Medicina $(n=25)$ e Nutrição $(n=16)$. Como compreender este cenário, uma vez que, desse universo é mínimo o quantitativo de professores que não possui mestrado e doutorado? Ele poderia estar relacionado a entendimentos e vivências diferentes dos docentes acerca do que seja pesquisa? Ou, ainda, por compreenderem o que é pesquisa e suas implicações (dedicação, disciplina, tempo, competências, habilidades) optam por não mais fazer pesquisa? Como adverte Bell (1985), ultrapassando a intenção de operar em investigações científicas, há 'domínios' imprescindíveis e, portanto, necessários à sua realização, a exemplo do campo conceptual e teórico.

Esta é uma questão que demanda estudo e investimento institucional, em face da importância da pesquisa na vida acadêmica, sobretudo no desenvolvimento social. Formar profissionais com capacidade de responder às necessidades de um mundo revolucionado por via de relações virtuais, por individualidades que não sobrevivem no isolamento, por avanços tecnológicos que a todo instante submetem a xeque os saberes e práticas instituídas não é tarefa simples. A ordem epistemológica atual demanda dos profissionais dos mais variados setores da sociedade modos dinâmicos e situados de aprender, criar e reinventar o conhecimento, o que se faz pela pesquisa.

É neste panorama social que se ancora a contribuição deste estudo, cujos achados, entre outros potenciais, oferecem pistas para o delineamento de ações a serem formuladas no âmbito do desenvolvimento profissional dos docentes da UECE, tendo em vista tanto a melhoria do ensino de graduação quanto o incremento da capacidade inovadora e produtora de conhecimento desta instituição.

A caracterização dos nove docentes que compuseram a amostra final deste ensaio revela um grupo heterogêneo de sujeitos no que concerne à formação acadêmica fortemente marcada pelo bacharelado e à atuação em pesquisa. Foram identificadas, nos cinco cursos investigados, discrepâncias no desenvolvimento de atividades de pesquisa em seu quadro docente, situação que demanda investimento institucional, com vistas a estimular o incremento dessa atividade, em particular, no curso de Educação Física.

Ter uma trajetória de experiência em pesquisa consolidada em momentos de formação e de práticas profissionais, para os professores investigados, distingue-se como fator importante para 
PESQUISA COMO PRINCIPIO EDUCATIVO | Silvia Maria Nóbrega-Therrien e et. al.

o desenvolvimento de ações que integram pesquisa e ensino em situação de sala de aula. Essa observação, contudo, deve ser ponderada porquanto nem sempre, docentes com tradição de pesquisa, demonstrem êxito nessa tarefa ou reconheçam sua importância para a formação. Debita-se a raiz desse problema à dificuldade de compreender a pesquisa também como estratégia para articular teoria e prática, no contexto do ensino, certamente devedora da acepção de pesquisa acadêmica, na formação e na cultura universitária. Os dados referentes aos cursos analisados revelam diversidades de compreensão quanto a esse fenômeno.

De modo geral, a análise permite assegurar que as iniciativas identificadas de integração pesquisa e ensino são esparsas e frágeis, tanto do ponto de vista da própria ação empreendida pelo professor (a prática), quanto sob a ótica conceitual (da compreensão que detém sobre esse processo e sua importância na formação). Também restou constatado o fato de que as práticas pedagógicas desenvolvidas pelos professores, nos cinco cursos de graduação investigados, abrem pouco espaço para a integração pesquisa e ensino. A transmissão do conteúdo ainda prevalece como preocupação central na ação dos professores acompanhados na pesquisa, secundarizando-se o debate, a exploração de situações problemas, da prática profissional e da argumentação, como vias férteis para a promoção de aprendizagens que ultrapassem a memorização e a reprodução.

Mesmo não constituindo prática robusta e frequente no fazer pedagógico dos docentes acompanhados nos cinco cursos de graduação, é possível afirmar-se que há uma tendência a reconhecer a pesquisa e a utilizá-la como estratégia de ensino e de aprendizagem. A presença da pesquisa, de modo transversal na gestão do saber curricular e na formação dos alunos, é mais visível entre os docentes com inserção em programas de iniciação científica, grupos de pesquisa ou desenvolvendo projetos. O reconhecimento da pesquisa e seu impacto para a aprendizagem, quando integrada ao ensino, constituem fator muito mais de afirmação teórica do que a realidade, efetivamente prática no trabalho docente.

Evidencia-se ainda, a inexistência, na Instituição, de uma política de alocação de professores para as disciplinas da área de pesquisa. Os dados analisados indicam uma tendência a não se considerar sequer a titulação, o vínculo, a experiência ou a participação em grupos de pesquisa, para a lotação de professores em disciplinas que requerem domínio do campo de investigação, embora pesquisar seja um dos objetivos precípuos da Universidade e um componente curricular de formação inseparável do ensino, considerando a integração da produção de saberes e a aprendizagem destes.

Os dados indicam, também, que professores com experiência consolidada de pesquisa exprimem um modo diferenciado de lecionar e de desenvolver a atitude investigativa em seus alunos. De modo geral, se percebe nestes docentes, uma valorização da participação ativa dos alunos e uma prática que promove, nos aprendizes, certas habilidades que os acompanharão durante o processo de construção do conhecimento. Assim sendo, deve-se investir, para que modos de práxis docente, com este referencia, possam constituir a tônica da cultura pedagógica na universidade, o que resulta em ações urgentes e necessárias. 
PESQUISA COMO PRINCIPIO EDUCATIVO | Silvia Maria Nóbrega-Therrien e et. al.

\section{Referências}

ANDRÉ, M. E. D. A. de. Pesquisa, formação e prática docente. In: O papel da pesquisa na formação e na prática dos professores. Campinas: Papirus, 2001. p. $55-70$.

O papel mediador da pesquisa no ensino da didática. In: ANDRÉ, M. E. D. A. de; OLIVEIRA, M. R. (Org.). Alternativas no ensino de didática. Campinas: Papirus, 1997.

BELL, J. Doing your research: a guide for first-time researchers in education and social science. Milton Keynes: Open University, 1985.

CUNHA, M. I. O professor universitário na transição dos paradigmas. Araraquara-SP: J. M. Editora, 1998.

DEMO, P. Pesquisa: principio científico e educativo. 8. ed. São Paulo: Cortez, 2001.

FARIAS, I. M. S. de. Cultura docente e mudança na prática de ensino. In: SALES, J. A. M. Formação e Práticas Docentes. Fortaleza: EdUECE, 2007. p. 151164.

LÜDKE, M. O professor e a pesquisa. Campinas: Papirus, 2001.

NÓBREGA-THERRIEN, S. M.; THERRIEN, J. Ensino e pesquisa nos cursos de graduação em Educação e Saúde: apontamentos sobre a prática e análise dessa relação. Revista da FACED, Salvador, n. 10, p. 279293, 2006.

PIMENTA, S. G. Pesquisa e formação de professores: contextualização histórica e epistemológica de um projeto Integrado. In: GUIMARÃES, V. S. (Org.). Formação para o mercado de trabalho ou para autonomia?: o papel da universidade. Campinas: Papirus, 2006. p. 67-89.
SACRISTÁN, J. G. Poderes instáveis em educação. Porto Alegre: Artes Médicas, 1999.

SCHÖN, D. The reflective practitioner. New York: Basic Book, 1983.

Educando o profissional reflexivo: um novo destaque para o ensino - o ensino e a aprendizagem. Porto Alegre: Artes Médicas, 2000.

THERRIEN, J.; LOIOLA, F. A. Experiência e competência no ensino: pistas de reflexões sobre a natureza do saber-ensinar na perspectiva da ergonomia do trabalho docente. Educação e Sociedade, n. 74, p. 143-162, 2001.

THERRIEN, J.; NÓBREGA-THERRIEN, S. M. Formação para além do ensino. In: SALES, J. A. M. de; BARRETO, M. C.; FARIAS, M. I. S. de. (Org.). Docência e formação de professores: novos olhares sobre temáticas contemporâneas. Fortaleza: EdUECE, 2009. p. 99-108.

THERRIEN, J. Docência profissional: a prática de uma racionalidade pedagógica em tempos de emancipação de sujeitos. In: D’AVILA, C.; VIEGA, I. P. A. (Org.). Didática e docência na educação superior: implicações para a formação de professores. Campinas: Papirus, 2012. p. 109-132.

ZEICHNER, K. M. A formação reflexiva de professores: ideias e práticas. Lisboa: Educar, 1993.

Para além da divisão entre professor-pesquisador e pesquisador acadêmico. In: GERALDI, C. M. C.; FIORENTINI, D.; PEREIRA, E. M. de A. Cartografias do trabalho docente: professor(a)-pesquisador(a). Campinas: Mercado de Letras, 2003. p. 207-237. 